\title{
Research on fault of turn to turn short circuit of rotor winding of large hydro generator
}

\author{
Meiqi Song \\ School of electric power engineering, North China Electric Power University, Baoding 071000, \\ China.
}

987353464@qq.com

\begin{abstract}
Keywords: Hydro Generator, Fault of Rotor Winding Inter-turn Short Circuit, Failure Criteria
\end{abstract}
\begin{abstract}
With the rapid development of hydropower, the fault of roto winding inter-turn short circuit of large hydro generator set is more and more obvious. We did the research of fault mechanism of turn to turn short circuit of rotor winding of hydro generator, and concerned the condition of saturation of the generator. After a series of deductions, we obtain the following criteria, $\frac{I_{f c}-I_{f 0}}{I_{f 0}}>\alpha \%$. In the formula, $\alpha \%$ general take $1 \% \sim 2 \%$. In the actual working conditions, using the formula to calculate the normal operation of the excitation current, compared with the actual measured value, if the deviation is large, it can be determined whether the turn to turn short circuit fault.
\end{abstract}

\section{Introduction}

In recent years, the research on rotor winding inter turn short circuit fault of large turbo generator (pole machine) has made great achievements ${ }^{[1,2]}$. However, with the rapid development of hydropower, more and more attention is paid to the fault of rotor winding inter turn short circuit fault of large hydro generator set. We are committed to the research of fault mechanism of turn to turn short circuit of rotor winding of hydro generator, taking the fault of the rotor winding inter turn short circuit under the condition of saturation of the generator into account. According to the fault causes and the analysis of real-time acquisitioned data, the corresponding relationship between the magnetic field loss and the electrical parameters is found, and then we can determine the fault characteristics. Finally, according to the fault characteristics, an effective and practical fault criterion is proposed

\section{Analysis of electrical parameter variation and determination of the fault criterion}

\subsection{Electrical Parameter Variation Rotor Winding Inter-turn Short Circuit Fault of large turbo generator}

On the basis of the research on the characteristics of rotor winding inter turn short circuit of hydropower ${ }^{[3,5]}$, We have studied the electromagnetic state and the measurable change of the rotor turn to turn short circuit, and then, the corresponding relationship between the loss of the rotor winding inter turn short circuit and the change of electrical parameters of it are obtained.

From the point of view of the MMF conservation, the decrease of effective number of turns of excitation winding, cause the decrease of rotor magnetomotive force $F$, and the electromagnetic quantity of the stator is constant, so the excitation current will increase and cause the rotor magnetomotive force $F$ increases to the level without fault. Electromagnetic power is sent through the coupling air gap magnetic field. When the rotor turn to turn short circuit fault occurs, the number of turns of rotor is reduced, the ability of the generator to supply the magnetic field weakens, which leads to the decrease of the energy exchange capacity of the air gap magnetic field, and the reactive power output is bound to decline. Turn to turn short circuit does not affect the power input of original motive mechanical, the output of the active power is not changed a lot, so we can say that the active power is constant. 


\subsection{Determination of the fault criterion}

Hydro short circuit occurs between the windings of the rotor causes the fault characteristics, such as excitation current increases, significantly reduced reactive power, active unchanged. These electrical quantities can be used to identify the characteristic of turn to turn fault. By measuring generator terminal information, such as the voltage, current, active power, reactive power, excitation voltage, and the corresponding excitation current is calculated by the accurate mathematical model of the measured electrical quantities. The calculated value is compared with the measured excitation current, so as to judge whether there is a rotor turn to turn short circuit fault and to evaluate the degree of the fault ${ }^{[4]}$. Failure criteria is as follow:

$$
\frac{i_{f c}-i_{f 0}}{i_{f 0}}>\alpha \%
$$

The standard value of excitation current calculation $i_{f 0}$, it is compared with the actual measured value of the exciting current $i_{f c}$ to determine whether the generator rotor winding turn to turn short circuit fault occurs. ( $\alpha \%$ is the deviation relative value which has concerned the calculation error and measurement error, the occurrence of rotor turn to turn short circuit can be judged by the situation that the comparison value is greater than the $\alpha \%$ )

\section{The numerical calculation method of the standard value of the exciting current}

We consider the case of the rotor winding inter-turn fault in the case of the saturation of the core. At this point, $E_{0}$ and $I_{f}$ into a non-linear relationship, $I_{f}$ is usually determined by the mapping $\operatorname{method}^{[6,7]}$.

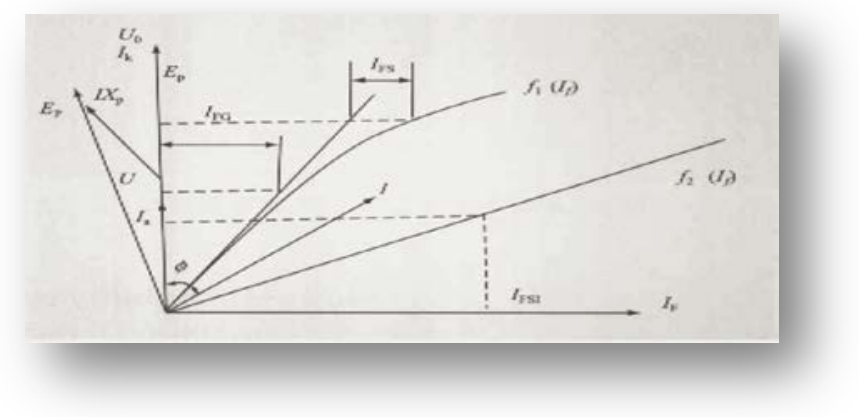

Figure 1

Take the voltage vector $U$ in the vertical coordinate, and make the current vector according to the load power factor angle. Ignore the value of the stator resistance $R$, Voltage vector $U$ is used to make the voltage drop of $I X_{p}$, which is perpendicular to the current vector $I$, to obtain the potential of the ladder $E_{p}$.

The calculation formula is as follows:

$$
\mathrm{E}_{p}=\sqrt{(U \cos \phi)^{2}+\left(U \sin \phi+I X_{P}\right)^{2}}
$$

Then, when the $\mathrm{E}_{p}$ value is taken in the vertical coordinate, the line is parallel to the horizontal axis and the air gap line and the no-load characteristic curve are respectively, and the difference of the excitation is $I_{F S}$. The excitation current $I_{F G}$ which is of the corresponding load stator voltage $U$, is obtained on the no-load characteristic air gap curve. The excitation current $I_{F S I}$ which is of the corresponding load stator currents $I_{a}$, is obtained in the steady state short circuit characteristics curve.

The load excitation current $I_{F L}$ is calculated for the vector diagram: 


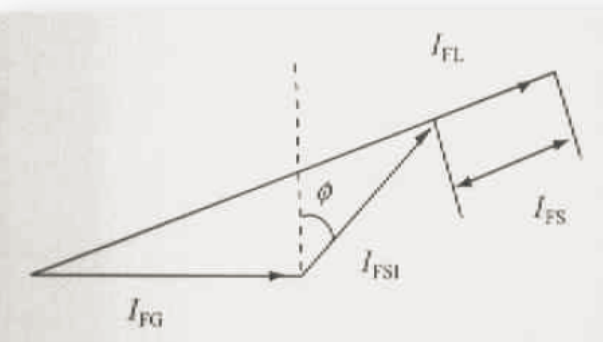

Figure 2

$$
I_{F L}=I_{F S}+\sqrt{\left(I_{F S I} \cos \phi\right)^{2}+\left(I_{F S I} \sin \phi+I_{F G}\right)^{2}}
$$

In order to reduce the random error, we can apply the Matlab curve fitting module, to fitting the motor no-load characteristic curve and short circuit characteristic curve. We can deduce the mathematical expression of $E_{0}$ and $I_{f}$ in the unsaturated condition, and then transform the graphic method into the numerical calculation method.

\section{Feasibility verification}

In order to verify the feasibility of the calculation method, the motor of the model TZH-225-TH produced by Lanzhou motor Limited by Share Ltd was applied to calculate the excitation current. Curve fitting by no-load characteristic parameter, as shown in the Figure 3.

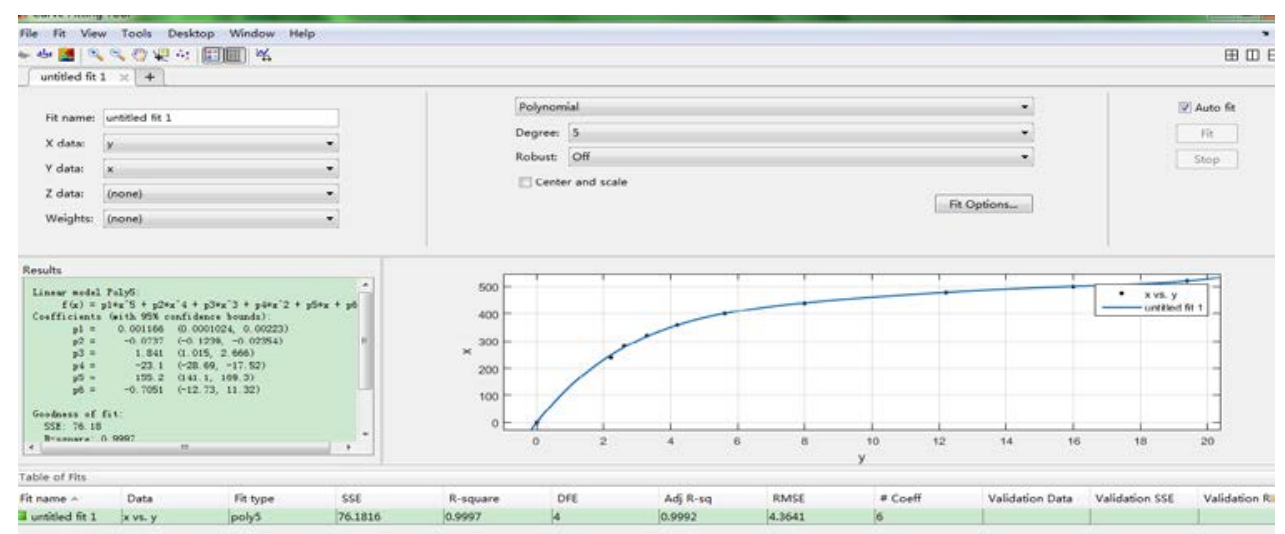

Figure 3 MATLAB Fitting the no-load characteristic curve of the experimental motor

Translate the relevant data into an expression as $E_{0}=f\left(I_{f}\right)$,

$$
E_{0}=0.001166 \times I_{f}^{5}-0.0737 \times I_{f}^{4}+1.841 \times I_{f}^{3}-23.1 \times I_{f}^{2}+155.2 \times I_{f}-0.7051
$$

Continue to be deformed in the form of $I_{f}=f\left(E_{0}\right)$

$$
\begin{aligned}
I_{f} & =2.253 \times 10^{-12} \times E_{0}^{5}-1.253 \times 10^{-9} \times E_{0}^{4}-1.523 \times 10^{-8} \times E_{0}^{3} \\
& +0.0001196 \times E_{0}^{2}-0.008993 \times E_{0}+0.0002891
\end{aligned}
$$

Through this type can be more convenient to calculate the normal operation of the motor excitation current.

\section{Summary}

For a hydraulic turbine, a set of experimental data, we calculate the corresponding $I_{f}$ in a certain state of the excitation current calculation standard value $I_{f 0}$, compare it with the actual measured value of exciting current $I_{f c}$, we can determine whether the generator rotor winding 
inter-turn short circuit fault occurs. The criterion is

$$
\frac{I_{f c}-I_{f 0}}{I_{f 0}}>\alpha \%
$$

In the formula, $\alpha \%$ is the deviation relative value which has concerned the calculation error and measurement error, general take 1\% 2\%. In the actual working conditions, using the formula to calculate the normal operation of the excitation current, compared with the actual measured value, if the deviation is large, it can be determined whether the turn to turn short circuit fault.

\section{Reference}

[1] Li Yonggang, Li Heming, A New Method for Fault Analysis and Diagnosis of Interturn In Turbo-Generator Roter, Automation of Electric Power Systems, 1998.

[2] Li Yonggang, Li Heming, Zhao Hua, The New Criterion on Inter Turn Short-Circuit Fault Diagnose of Steam Turbine Generator Rotor Windings, Proceedings of the CSEE, 2003.

[3] Hao Liangliang, Sun Yuguang, Qiu Arui, Wang Xiangheng, The Steady-state Fault Characteristics of a Large Hydro-generator with Inter-turn Short Circuit of Field Windings, Automation of Electric Power Systems, 2011.

[4] Lu Ran, Research on Fault Diagnosis of Generator Rotor Winding Inter-turn Short Circuit, (Master, North China Electric Power University, China, 2011)

[5] Shi Wei, Study on Fault of Turn to Turn Short Circuit of Rotor Winding of Hydro Generator, (Master, North China Electric Power University, China, 2012)

[6] Wang Hongze, Analytical Calculation Method for Rotor Excitation Current of Synchronous Generator, Large Electric Machine and Hydraulic Turbine, 1982.

[7] Guan Jianjun, Fu Ziqing, Excitation Current Calculation on Load for Synchronous Generators, Electric Power, 2003.

[8] Yang Jianhua, Gao Jun, Field Current Calculation of Synchronous Generators Taking into Account the Magnetic Saturation, P roceedings of the CSU 2EPSA, 2009.

[9] Zhao Wei, Xian Zhelong, Li Lijun, Calculation and Analysis of 1100MW Type QNSN-1100-4 Generator Excitation Current, Shanghai Medium and Large Electrical Machines, 2010. 